In Crescendo, 2020; 11(2): 241-258

Fecha de recepción: 21/09/2019

Fecha de aceptación: 04/05/2020

\title{
LA EDUCACIÓN TRIBUTARIA EN EL PERÚ: UNA ALTERNATIVA PARA MEJORAR EL CUMPLIMIENTO DE LAS OBLIGACIONES TRIBUTARIAS
}

\author{
TAX EDUCATION IN PERU: AN ALTERNATIVE TO IMPROVE \\ FULFILLMENT OF TAX OBLIGATIONS
}

Gebson R. Cárdenas ${ }^{1}$

\section{RESUMEN}

En el Perú, el cumplimiento de la obligación tributaria se encuentra establecida bajo el modelo de la autodeterminación del tributo, que además implica cumplir con diversos deberes formales, cuya exigencia puede ser coaccionada por el fisco, esta coerción implica una cobranza forzosa al contribuyente por parte de la Superintendencia de Aduanas y Administración Tributaria (SUNAT) quien es la encargada de administrar los tributos y aplicar la normatividad para el control y fiscalización de la obligación tributaria. Sin embargo, a pesar de que la ley ha facultado a la Administración Tributaria realizar la fiscalización y cobranza de los tributos, la Administración no ha logrado mejorar el cumplimiento tributario, ni erradicar la evasión tributaria y el contrabando. El presente artículo, aborda el estudio de la cultura tributaria frente al incumplimiento de obligaciones tributarias. La conciencia tributaria implica que la ciudadanía comprenda el rol social de los impuestos a partir de procesos educativos, es así que, se describe la importancia de la enseñanza de la tributación desde el sistema educativo básico.

PALABRAS CLAVE: Obligación; evasión tributaria; cultura tributaria.

1 Maestro en Política y Gestión Tributaria. Funcionario de la Superintendencia Nacional de Aduanas y Administración Tributaria - SUNAT. gcardenasr7@gmail.com; http://orcid.org/0000-0003-33768713 


\begin{abstract}
In Peru compliance with the tax obligation is established under the model of selfdetermination of the tax, which also involves fulfilling various formal duties, whose demand may be coerced by the Treasury, this coercion implies a forced collection to the taxpayer by the taxpayer. the Superintendency of Customs and Tax Administration (SUNAT) who is in charge of administering the taxes and applying the regulations for the control and supervision of the tax obligation. However, despite the fact that the law has empowered the Tax Administration to carry out the inspection and collection of taxes, the Administration has not been able to improve tax compliance or eradicate tax evasion and contraband. This article addresses the study of the tax culture in the face of non-compliance with tax obligations. Tax awareness implies that the citizenry understands the social role of taxes from educational processes, thus, the importance of teaching taxation from the basic education system is described.
\end{abstract}

KEY WORDS: Obligation; tax evasion; tributary culture.

\title{
INTRODUCCIÓN
}

En el Perú al igual que en los países de América Latina, los gobiernos de turno a través de sus Administraciones Tributarias han implementado estrategias fiscales para contrarrestar las prácticas de la evasión tributaria. Sin embargo, los esfuerzos por controlar su cumplimiento no han sido lo suficientemente efectivos, debido a que la corrupción ha afectado considerablemente la credibilidad de las autoridades públicas y de las instituciones del estado, reflejando una crisis de valores y conductas que crean una conciencia tributaria débil en relación al cumplimiento sustancial de los tributos, acompañado de la negativa del administrado por cumplir con los deberes formales que se encuentran asociados al cumplimiento del pago de impuestos, es por ello que surge una reciprocidad de la cultura tributaria frente a la ética y el cumplimiento de la ley. En el caso peruano, la Superintendencia de Aduanas y Administración Tributaria (SUNAT) ha utilizado diversos instrumentos fiscales para controlar las conductas evasivas de los contribuyentes, adicionalmente estas estrategias han buscado lograr la formalización de actividades empresariales y de personas naturales. Sin embargo, no han sido consecuentes en permitir un cambio en la conducta del contribuyente, partiendo de la premisa de que se hace necesario crear hábitos para el cumplimiento voluntario de las obligaciones tributarias desde un enfoque sustancial y formal de las obligaciones, reto que ha sido asumido por cada gobierno de turno a través de sus políticas fiscales, y que han sido ejecutados total o parcialmente por sus Adminis- 
traciones Tributarias, pero que aún no han sido materializados en lograr la ampliación de la base tributaria, y un incremento en la recaudación de impuestos.

Según la Superintendencia de Aduanas y Administración Tributaria (SUNAT, 2001) afirma:

Un elemento clave para lograr una mayor recaudación es el cumplimiento voluntario de las obligaciones tributarias por parte de los ciudadanos. Para ello es necesario que las personas asuman la tributación como un compromiso que forma parte de sus deberes y derechos como ciudadanos integrantes de una comunidad, como agentes activos del proceso y no en forma pasiva. Un agente activo es un ciudadano que toma conciencia de su modo de actuar en sociedad, es más participativo y crítico, acepta las normas y cumple con sus obligaciones por convicción, lo que lo faculta a exigir el respeto y el cumplimiento de sus derechos. (p.56)

La Administración Tributaria peruana resalta la importancia del cumplimiento voluntario de las obligaciones tributarias en relación al incremento de su recaudación. Sin embargo, el escenario que la Administración no ha considerado que existe un gran segmento de contribuyentes que no son coaccionados para el cumplimiento de sus obligaciones por el simple hecho de no tener el registro único del contribuyente (RUC), pretender el cumplimiento voluntario del sector formal resulta incongruente para aquel segmento que realiza sus actividades empresariales en la informalidad, y sobre el cual la Administración no ha logrado tener éxito en su control y formalización, urgen estrategias orientadas a la educación y conciencia de la ciudadanía sobre el rol social de los tributos. El cumplimiento tributario bajo el enfoque tradicional de la coacción ha generado que el administrado perciba a la Administración Tributaria como abusiva y autoritaria, es oportuno ante esta situación, cambiar la percepción del contribuyente hacia una Administración Tributaria justa, para ello resulta necesario formar en los ciudadanos cultura tributaria.

La Corporación Latinobarómetro (Latinobarómetro, 2010) señala que:

El hecho de que exista la percepción de que aproximadamente la mitad de la población de la región paga sus impuestos debidamente, implica que la otra mitad no lo hace. Este es el problema principal de las políticas públicas. El Estado es percibido con potestad para solucionar problemas, pero no puede solucionar su problema principal que es convencer a sus ciudadanos que sin impuestos no tiene la potestad. Esto es una situación imposible, porque tiene demandas, pero 
no tiene la buena voluntad de la población para pagar los impuestos de tal manera que pueda cumplir con la satisfacción de las demandas. (p.88)

El incumplimiento de las obligaciones tributarias por parte de los ciudadanos peruanos se ve reflejado en la problemática de la evasión tributaria, la informalidad y el contrabando, por ello, urge que el estado a través de su Poder Ejecutivo y la Administración Tributaria establezcan acciones que coadyuven a educar sobre el rol social del tributo; en tal sentido, se puntualiza la necesidad de educar y fomentar la conciencia tributaria, siendo estratégicamente necesario partir desde los niveles de la educación básica regular, todo ello unido a recuperar la formación en valores de los ciudadanos. En tal sentido, corresponde a la Administración Tributaria en cooperación con los centros educativos asumir el compromiso de formar ciudadanos a mediano plazo capaces de hacer cumplir reglas de convivencia relacionados a la tributación.

\section{ARGUMENTACIÓN}

\section{Reflexiones sobre el sistema tributario peruano}

La tributación en el Perú como en otros países de América Latina se encuentra constituida por la política fiscal, el sistema tributario y la administración tributaria. La política fiscal parte de una política pública que ciertamente resulta ser la más importante. Samuelson y Nordhaus (2004) afirman que: "La política fiscal está conformada por el gasto público e impuestos. El gasto del gobierno influye en la dimensión relativa del gasto colectivo y del consumo privado. Los impuestos sustraen ingresos, reducen el gasto privado y afectan al ahorro privado" (p.401).

El Instituto de Administración Tributaria y Aduanera de la SUNAT (ahora Instituto Aduanero y Tributario) (IATA, 2010) señala que:

La política fiscal es un conjunto de orientaciones que configura el presupuesto del Estado y sus componentes, el gasto público y los impuestos. La política tributaria afecta casi todos los aspectos de la economía y la sociedad. El tamaño del estado, la magnitud de la redistribución de la riqueza y las decisiones de consumir e invertir están relacionadas con este campo fundamental de la política. Dados los grandes efectos que puede tener en la eficiencia y la equidad, la política tributaria, tal vez, sea el campo de la política pública donde existen más intereses en juego. (p.75) 
Por su parte, el sistema tributario peruano de acuerdo a las facultades delegadas en el Decreto Legislativo N.. 771 establece un conjunto de normas y principios que crean y regulan la aplicación de tributos, cuyos objetivos principales establecen incrementar la recaudación y brindar al sistema tributario una mayor eficiencia, permanencia y simplicidad cuya norma fundamental se encuentra recogida en el código tributario, en este contexto Bravo (2006) señala:

Cuando hablamos de Sistema tributario, nos estamos refiriendo al conjunto de normas jurídicas que establecen tributos y las que regulan los procedimientos y deberes formales necesarios para hacer posible el flujo de tributos al Estado, asî como las que contienen los principios del Derecho Tributario, usualmente sedimentadas en el texto Constitucional. En ese escenario, el Sistema tributario es más amplio que Régimen tributario, qué sólo se refiere a las normas referidas a los tributos. (p.87)

Los distintos tributos que conforman el sistema tributario, no se transcriben en un simple acto de pagar el tributo, las relaciones que se originan en la aplicación de tributos establecidos en el código tributario resultan ser amplios y complejos, es por ello que Bravo (2006) sostiene que: "El código tributario no es el código de la administración tributaria, es más bien la norma que regula las relaciones entre los sujetos que rodean el fenómeno tributario y sus consecuencias económicas y jurídicas" (p.87). La potestad tributaria se encuentra limitada por los principios constitucionales que instituyen fundamento del sistema tributario, en este contexto el artículo $74^{\circ}$ de la Constitución Política del Perú establece que los tributos se crean, modifican o derogan, o se establece una exoneración, exclusivamente por ley o decreto legislativo en caso de delegación de facultades, salvo los aranceles y tasas, los cuales se regulan mediante decreto supremo. En este contexto, la constitución ha recogido expresamente los principios de legalidad, reserva de la ley, igualdad, no confiscatoriedad y los derechos fundamentales de la persona como fundamento del sistema tributario. Sin embargo, a lo largo de los años se ha instituido principios como el deber de contribuir y el principio de solidaridad como elementos importantes en el cumplimiento de obligaciones tributarias, es así que el Tribunal Constitucional (TC, 2006) en el expediente N.. 6626-2006-PA/TC ha establecido que:

La búsqueda de una sociedad más equitativa, propia del Estado Social y Democrático de Derecho, se logra justamente a través de diversos mecanismos, entre los cuales la tributación juega un rol preponderante y esencial, pues mediante ella cada ciudadano, respondiendo a su capacidad contributiva, aporta parte de 
su riqueza para su redistribución en mejores servicios y cobertura de necesidades estatales (...). El Estado Social y Democrático de Derecho, el fundamento de la imposición no se limita únicamente a una cuestión de Poder Estatal, sino que incorpora a su razón de ser, el deber de todo ciudadano al sostenimiento de los gastos públicos, deber que, si bien originalmente fuera entendido respecto al cumplimiento de obligaciones sustanciales y formales relacionadas con el pago, también podría extenderse a la exigencia de cuotas de colaboración de terceros con la Administración Tributaria. La transformación de los fines del estado determinará que se pase de un deber de contribuir, basado fundamentalmente en la capacidad contributiva, a un deber de contribuir basado en el principio de solidaridad (...). En este tipo de Estado el ciudadano ya no tiene exclusivamente el deber de pagar tributos, concebido según el concepto de libertades negativas propio del Estado Liberal, sino que asume deberes de colaboración con la Administración, los cuales se convertirán en verdaderas obligaciones jurídicas. En otras palabras, la transformación de los fines del Estado determinará que se pase de un deber de contribuir, basado fundamentalmente en la capacidad contributiva, a un deber de contribuir basado en el principio de solidaridad.

Ahora bien, el tributo como conducta de dar una suma de dinero al estado, se encuentra sometida a reglas de la potestad tributaria que establece en rigor el cumplimiento de los principios constitucionales, de derecho y aquellas incorporadas mediante la jurisprudencia del Tribunal Constitucional. En este contexto, el contribuyente asume un rol de cooperación con la Administración Tributaria frente a la obligación tributaria, generándose una participación simultánea del administrado y la Administración Tributaria para la consecución de los fines del Estado.

La Superintendencia Nacional de Aduanas y de Administración Tributaria, de acuerdo a su Ley de creación N.ㅇ 24829 y la Ley N. 29816 de Fortalecimiento de la SUNAT, entre sus finalidades, tiene como finalidad primordial administrar los tributos del gobierno nacional y los conceptos tributarios y no tributarios que se le encarguen por Ley o de acuerdo a los convenios interinstitucionales que se celebren, proporcionando los recursos requeridos para la solvencia fiscal y la estabilidad macroeconómica; así también, tiene la obligación de proveer a los administrados los servicios que faciliten el cumplimiento de sus obligaciones tributarias, así como brindar servicios a la ciudadanía en general dentro del ámbito de su competencia. Es así que, el artículo $84^{\circ}$ del Texto Único del Código Tributario aprobado por Decreto Supremo N. - 133-2013-EF, establece la obligación de la 
Administración en proporcionar orientación, información verbal, educación y asistencia al contribuyente.

$\mathrm{Al}$ respecto, resulta evidente que facilitar el cumplimiento de las obligaciones tributarias y deberes formales para los contribuyentes, demanda de una Administración Tributaria que proporcione al administrado información y atención de calidad para facilitar el cumplimiento de sus obligaciones, además, resulta pertinente citar el malestar que ocasiona la inadecuada orientación de la Administración a los ciudadanos, lo cual significa que se requiere el mejoramiento de los centros de atención al contribuyente.

Por otra parte, la legislación tributaria en el Perú establecen reglas tanto para el contribuyente y la Administración Tributaria; el administrado tiene la obligación de conocer sobre las formalidades que amerita la aplicación de tributos, es así que, el modelo peruano establece la autoliquidación de la obligación tributaria, es decir, el administrado es quien verifica la realización del hecho generador de la obligación tributaria, identificando su base imponible y la cuantía del tributo, tal como lo establece el Código Tributario peruano. Sin embargo, tal determinación resulta ser incomprensible para el contribuyente al encontrarse con hasta cuatro regímenes tributarios con particularidades distintas respecto a las obligaciones accesorias, a ello se le suma los regímenes especiales que contempla la normatividad tributaria; para ello, corresponde a la Administración Tributaria brindar los servicios que faciliten el cumplimiento de las obligaciones tributarias. Sin embargo, el sistema tributario por la variedad de regímenes y particularidades de los deberes formales resultan ser complejos para el administrado. Además, la ciudadanía percibe una desorientación por parte de la SUNAT en los procedimientos tributarios y de atención al contribuyente, es por ello que la aplicación de los tributos y el cumplimiento de sus obligaciones de por sí resulta amplio y complejo, teniendo en cuenta el escenario peruano donde el administrado podría encontrarse desinformado y con una débil cultura tributaria.

\section{Cumpliendo e incumpliendo las obligaciones tributarias}

En la doctrina del derecho Osterling y Castillo (2001) afirman que la obligación:

Constituye una relación jurídica que liga a dos o más personas, en virtud de la cual una de ellas, llamada deudor, debe cumplir una prestación a favor de la otra, llamada acreedor, para satisfacer un interés de este último digno de protección. 
Dentro de esa relación jurídica corresponde al acreedor el "poder" o "derecho de crédito" para exigir la prestación. Si el deudor, vinculado en tal forma, no cumple la prestación, o la cumple defectuosamente, por razones a él imputables, responde con sus bienes de dicho incumplimiento, en razón del elemento coercitivo previsto por la ley. (p.101)

Por su parte, el código tributario peruano establece que la obligación tributaria es de derecho público, cuyo vínculo entre el acreedor y el deudor tributario establecido por ley, tiene por objeto el cumplimiento de la prestación tributaria, tal definición es concordante con lo señalado en la doctrina, puesto que, establece el supuesto del cumplimiento de una prestación del administrado hacia el estado, asimismo, el código tributario establece que obligación tributaria nace cuando se realiza el hecho previsto en la ley, como generador de dicha obligación.

Valdivia (2014) sobre el nacimiento de la obligación tributaria sostiene:

La configuración del hecho imponible (aspecto material), su conexión con una persona, con un sujeto (aspecto personal), su localización en determinado lugar (aspecto espacial) y su consumación en un momento real y fáctico determinado (aspecto temporal), determinarán el efecto jurídico deseado por la ley, que es el nacimiento de una obligación jurídica concreta, a cargo de un sujeto determinado, en un momento también determinado. El vínculo obligacional que corresponde al concepto de tributo nace, por fuerza de la ley, de la ocurrencia del hecho imponible. (p.31)

El nacimiento de la obligación tributaria tiene su fuente en una norma legal y no está propiamente supeditada a la voluntad del acreedor y deudor, en efecto como lo explica Aguayo (2014):

Los hechos cuya realización determinan el nacimiento de la obligación tributaria, así como la cuantía del tributo a pagar, la fecha de vencimiento y los efectos del incumplimiento, están sometidos al mandato de diversas normas jurídicas, y no al arbitrio de las partes conformantes de la relación jurídica. Ciertamente, sin importar cuál sea la voluntad del sujeto activo y del sujeto pasivo, luego de la dación de la norma jurídica correspondiente, y de la realización del hecho imponible, el objeto de la obligación tributaria, es decir, la prestación con la que se debe cumplir, no puede modificarse (al menos, no puede modificarla el deudor tributario y no debería modificarla el Estado. (p.43) 
En efecto, dar cumplimiento a la obligación tributaria implica entregar una suma de dinero por parte del contribuyente al estado, es así que, el código tributario y la doctrina jurídica establecen que la obligación tributaria tiene como objeto el cumplimiento de la prestación tributaria, que incluso es ejercida coercitivamente. La Administración Tributaria enfrenta escenarios en la cual, los contribuyentes incumplen la obligación sustancial (pago), ello conlleva iniciar por parte de la Administración procedimientos de cobros forzosos a través de medidas cautelares. Además, la Administración enfrenta un escenario en la que el contribuyente no determina de forma verídica la obligación tributaria, es decir, omite declarar total o parcialmente sus ingresos o rentas, o incrementa sus gastos o costos a fin de determinar una menor obligación, por lo que, se configura las practicas evasivas por parte del administrado. En otro contexto, la Administración se enfrenta un sector que omite en su totalidad la determinación de la obligación tributaria, este sector es aquella que se encuentra inmerso en la informalidad.

Para Bravo (como se citó en Ruiz de Castilla, 2010) señala que: "La ley regula las relaciones entre el Estado y las personas naturales o jurídicas que tienen que cumplir con la obligación tributaria (pago) y/o ciertos deberes administrativos vinculados a aquélla. Esta clase de ley se conoce como norma tributaria" (p.78). La legislación tributaria establece deberes formales adicionales a la obligación sustancial, ello involucra que el administrado cumpla con obtener el número de registro único del contribuyente (RUC), presentar declaraciones mensuales, presentar registros y/o libros contables, entre otras obligaciones que son necesarias para el cumplimiento de la obligación tributaria.

\section{La evasión tributaria y los controles tributarios}

La evasión tributaria constituye uno de los factores que más ha limitado el mejoramiento de la recaudación tributaria del estado, puesto que, los contribuyentes siguen inmersos en el escenario del incumplimiento de las obligaciones tributarias y accesorias de estas, para Villegas (2001) afirma que: "La evasión es toda eliminación o disminución de un monto tributario producido dentro del ámbito de un país por parte de quienes están jurídicamente obligados a abonarlo y que logran tal resultado mediante conductas violatorias de disposiciones legales" (p.382). En este mismo sentido, Moreno y Moreno (2014) afirman que: "La evasión tributaria es el no pago de la obligación tributaria, por lo que resulta claramente sancionable hoy en día por nuestra legislación, debido a que se aprecia con meridiana claridad el incumplimiento de la obligación tributaria" (p.152). 
Por su parte, en similar criterio, Bascuñán (2007) afirma sobre la evasión tributaria lo siguiente:

Conducta ilícita del contribuyente, dolosa o culposa, consistente en un acto o en una omisión, cuya consecuencia es la disminución del pago de una obligación tributaria que ha nacido válidamente a la vida del Derecho, mediante su ocultación a la Administración Tributaria, en perjuicio del patrimonio estatal. La evasión tributaria o evasión de impuestos es una figura jurídica consistente en el impago voluntario de tributos establecidos por la ley. Es una actividad ilícita y habitualmente está contemplado como delito en la mayoría de los ordenamientos.

\section{La educación tributaria y el proceso de socialización del contribuyente}

Como se ha señalado en los párrafos precedentes, el contribuyente se encuentra inmerso a cumplir determinadas obligaciones para poder pagar un tributo, ello conlleva que el administrado tenga conocimientos mínimos sobre la legislación tributaria, pero aún más importante saber por qué pagar impuestos, además la incomprensión del rol social del impuesto ha permitido que el fenómeno de la evasión tributaria perjudique la recaudación del estado, e incida desfavorablemente en el financiamiento de necesidades públicas.

El legislador peruano ha planteado y ejecutado distintas medidas para mejorar el cumplimiento tributario, es así que, las reformas tributarias han creado distintos regímenes tributarios enfocados a la formalización de actividades comerciales, así también, dichas reformas han establecido un escenario de mayores obligaciones para quienes ya se encontraban en el padrón de la SUNAT. Sin embargo, los instrumentos utilizados no han resultado ser atractivos para la formalización de negocios y por otro lado han llenado de mayor carga al sector formal y los administrados con una débil conciencia tributaria no han asimilado y entendido a las reformas, esta situación ha confirmado la necesidad de impulsar una política fiscal que tome en cuenta el comportamiento y actitudes de los contribuyentes, en este sentido Valdenebro y Delgado (2010) señalan que:

No se puede llevar a cabo una política fiscal verdaderamente eficaz sin contar con el elemento humano que la diseña, que la aplica y aquel a quien se dirige. Todas las leyes tributarias y las planificaciones financieras concebidas en la mesa de despacho son estériles si no se presta la debida atención a las ideas, actitudes, motivaciones y formas de comportamiento de los poderes públicos y de los ciudadanos, a su moral personal y colectiva, a su grado de cohesión o de antagonismo, y a sus ideas más o menos compartidas sobre el modo de organizar la convivencia cívica (p.3) 
Ahora bien, formar conciencia tributaria resulta favorable para el cumplimento de las obligaciones tributarias, ello será posible de impulsarlo desde el ámbito de la educación cívica y diversos procesos educativos. Ysenck (como se citó en Valdenebro y Delgado, 2010) afirma que:

La conciencia cívica no es algo natural; es un producto social y, por tanto, resultado de la educación. Los valores éticos de justicia, solidaridad y cooperación son producto de procesos sociales donde, por ensayo y error, se ha llegado al convencimiento de que es más útil y eficiente integrarlos en la conducta (p.4)

Impulsar la educación de la tributación implica transmitir los conocimientos tributarios mediante la educación formal o no formal por parte de la SUNAT, ello conllevaría establecer programas con contenido tributario que puedan ser asimilados por el contribuyente e incidan en generar el cumplimiento voluntario de obligaciones. La fórmula adecuada para transmitir conocimientos es aquella que se impartiría desde las bases por el sector de la educación, en este sentido, contribuir en un proceso de socialización del contribuyente implica estratégicamente la cooperación de la SUNAT y el Ministerio de Educación (MINEDU).

El escenario de una educación no formal, tal como la SUNAT viene llevando a cabo las charlas tributarias y los programas de orientación al contribuyente, permiten informar al administrado sobre el sistema tributario, pero distinto sería el impacto, si los contenidos tributarios son desarrollados desde el sistema de educación básica y superior. La SUNAT (2012) afirma que: "Para mejorar el cumplimiento de las obligaciones tributarias no basta con fiscalizar y sancionar para que los ciudadanos cumplan voluntariamente con sus obligaciones fiscales, entonces es de suponer que existen otros elementos que intervienen para que el ciudadano decida cumplir dichos deberes" (p.39).

Solórzano (2008) sostiene que:

La forma en que el sistema educativo puede actuar transmitiendo el valor "deber tributario" como parte de los deberes sociales, puesto que el incumplimiento fiscal es una conducta asocial, influirá en la actitud que se adopte ante el sistema fiscal. Y éste es un factor decisivo para el cumplimiento tributario. No cabe duda de que la conducta fiscal adulta sería distinta si se educara adecuadamente desde niños y jóvenes de la sociedad, como ya se viene haciendo en otros países. El sistema educativo puede preparar a los jóvenes para el momento en que deban cumplir sus obligaciones como contribuyentes, impartiendo una serie de conocimientos básicos que expliquen el sentido, el alcance y la finalidad de los impuestos (p.13). 


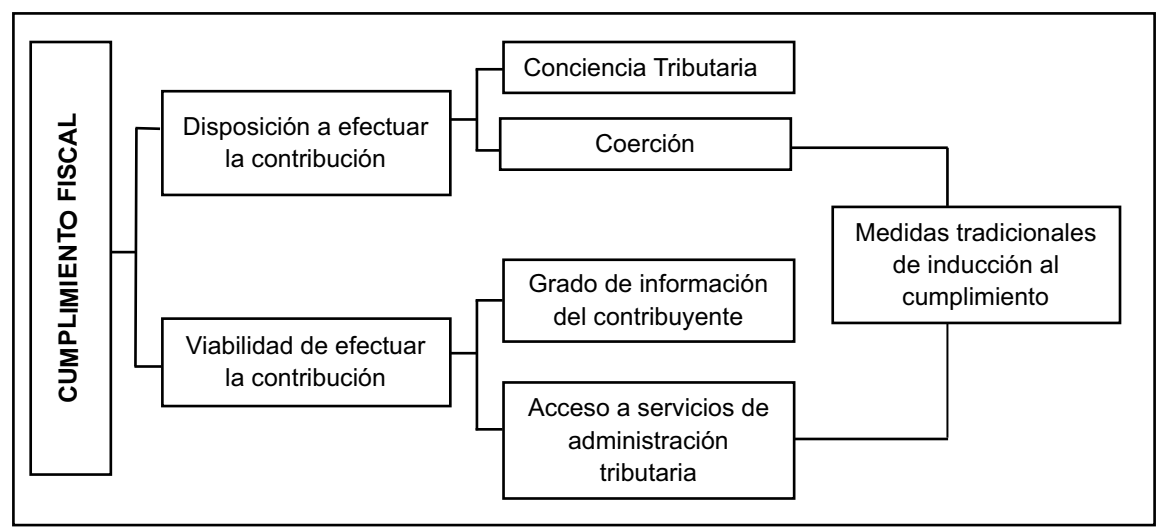

Figura 1. Elementos del cumplimiento fiscal. Fuente: Información obtenida de la Superintendencia Nacional de Aduanas y Administración Tributaria (2012)..

La alternativa de desarrollar contenidos tributarios a niveles de la educación básica regular, comprende la enseñanza de la normatividad con relevancia social, tales como el Código Tributario, las leyes del impuesto a la renta e impuesto general a las ventas, los procedimientos tributarios y el cómo estos contenidos tienen una relevancia social cuando la ciudadanía cumple con el pago de sus impuestos, bajo la perspectiva del cumplimiento voluntario. Además, debe comprender la enseñanza de contenidos accesorios con relevancia social, tales como el valor social de la Constitución Política y los procedimientos administrativos que salvaguarden los derechos de los administrados conforme lo establece la Ley $\mathrm{N} . \mathrm{o}$ 27444. Es en este sentido que, el Centro Interamericano de Administraciones Tributarias - CIAT (2019) sostiene que: "La Educación Tributaria, en algunos casos, en cooperación con los ministerios de educación, han creado secciones de contenido particular asociado a los estudios de ciudadanía y cívica o con materias específicas de tributación".

En esta línea de recomendación, cabe la pertinencia de replantear los convenios estratégicos suscritos por parte del Ministerio de Educación - MINEDU y la Administración Tributaria - SUNAT, ello conlleva a sostener que para el caso peruano el planteamiento de formar cultura tributaria parte desde el plano de la educación formal, es decir que, los contenidos tributarios y accesorios a estos, sean desarrollados desde las aulas de los colegios de la educación básica regular. La página Web de la SUNAT durante los últimos cinco años no ha publicado 
información, datos y estadísticas de cómo se viene ejecutando los contenidos tributarios en la escuelas, es por ello el llamado al Estado a replantear los objetivos estratégicos de los convenios antes descritos, en tanto, las reformas tributarias durante los últimos cinco años, solamente se han enfocado a la coacción de someter al contribuyente a cumplir sus obligaciones, mas no se ha logrado, que la población en general tenga la capacitación formativa mínima del por qué debe pagar impuestos.

Una regla básica de la tributación justa, fundamentada en el principio de capacidad contributiva, sostiene que los contribuyentes deben cumplir sus obligaciones de acuerdo a la capacidad de ingresos y consumos que tengan en un ejercicio, es decir, quienes tenga mayores ingresos serán quienes contribuyan más, a ello se le añade la regla del principio de solidaridad, que en buena cuenta ya fue ampliamente fundamentado por el Tribunal Constitucional, donde, es el deber de contribuir de cada peruano, que impulsa asumir con solidaridad la tributación que satisfaga las necesidades en fomento del desarrollo del país, en síntesis, sostener una tributación justa requiere tener a su ciudadanía debidamente informada y comprometida.

Instituciones internaciones han recomendado a las diferentes Administraciones Tributarias la importancia de fomentar cultura tributaria desde temprana edad, sin duda estratégicamente es pertinente capacitar a los docentes, quienes tendrán el papel indispensable de formar al estudiante. Además, resulta pertinente enfocar la enseñanza de contendidos tributarios desde los escenarios de la educación no formal, es decir mediante capacitaciones y charlas en los institutos y universidades. En esta línea de ideas, la Organización para la Cooperación y el Desarrollo Económicos - OCDE (2015) sostiene que: "Las administraciones son conscientes de la enorme dificultad que entraña cambiar la cultura fiscal sin educar desde edades tempranas a los futuros contribuyentes, o sin que los ciudadanos interioricen por convicción propia la responsabilidad de pagar sus impuestos. El fracaso de un Estado cualquiera para socializar los valores éticos de justicia, solidaridad e interés general puede traducirse en una barrera al cumplimiento" (p. 18).

La SUNAT ha comprendido la importancia de los programas educativos a nivel universitario, los diferentes países desarrollados han implementado núcleos de asesoría en materia tributaria y contable. Sin embargo, corresponde la difusión masiva de estos programas, a fin de que llegue a más personas. La SUNAT (2017), 
ha puesto en marcha: "El programa Núcleos de Apoyo Contable y Fiscal - NAF, el cual se viene implementando en diversas universidades e institutos de Lima y del interior del país. A través de este programa la SUNAT capacita de manera gratuita a estudiantes de las especialidades de Administración, Contabilidad, Economía, Derecho, Negocios Internacionales y carreras afines, en temas básicos de tributos y aduanas".

\section{Importancia de la educación y cultura tributaria}

Formar conciencia tributaria en la ciudadanía, pretende que los contribuyentes tomen conciencia sobre sus derechos y obligaciones frente al cumplimiento sustancial y deberes formales que involucra pagar impuestos, la importancia de impartir conocimiento tributario en la ciudadanía peruana, influye en la conducta del contribuyente ligado a la comprensión del rol social que tiene la tributación en la satisfacción de las necesidades públicas. Es en este sentido que, la enseñanza de contenidos tributarios y accesorios corresponden ser impartidos desde los colegios, mediante la educación formal, es decir la inclusión de contenidos tributarios en el currículo escolar. Asimismo, la pertinencia de implementar la educación no formal a nivel de la educación superior, mediante el desarrollo de capacitaciones, talleres y charlas en materia tributaria. Estos aspectos resultan estratégicamente de suma importancia en las actividades y objetivos que debe plantearse la Administración Tributaria - SUNAT, a fin de reducir en un mediano plazo los problemas vinculantes a la evasión tributaria e informalidad, y permitir la ampliación de la base tributaria y consecuentemente el incremento de la recaudación tributaria.

Giarrizzo (2014) afirma que:

Las sociedades modernas comprenden la importancia de los impuestos. Posiblemente aún queden resabios de esa vieja concepción del impuesto como imposición derivada de acciones caprichosas, arbitrarias y confiscatorias que rodearon históricamente al cobro de impuestos, y eso genere alguna resistencia a pagar. Por eso los controles y sanciones son necesarios. Pero sin olvidar que el buen comportamiento fiscal no es una habilidad. Es un valor que los gobiernos deben alimentar. No se construye sólo con controles y sanciones. Se edifica educando, incentivando, incorporando el pago fiscal como una acción voluntaria. Ideando un sistema tributario justo y equitativo. (p.68)

Para Valdenebro y Delgado (2010) afirman que: 
Si la socialización fiscal del ciudadano se basa en la adopción de los conceptos, normas, valores, actitudes y comportamientos propios de su familia, los de su círculo de amistades, los de su grupo profesional, y en los estilos de vida propuestos por los medios de comunicación, su conducta fiscal tenderá a ajustarse a lo que todos estos agentes socializadores esperen de él como contribuyente. Por lo que, si la conciencia fiscal de aquéllos es laxa y su comportamiento irresponsable, éste no juzgará poco ética su propia conducta fiscal incorrecta. (p.6)

La importancia de la tributación asociada al sistema educativo, conlleva a que los niños y jóvenes (pre contribuyente) en un mediano plazo posean conocimientos básicos que permitan comprender la finalidad de los tributos. La cultura tributaria tiene una relación favorable con el cumplimiento tributario, en este sentido, Armas (como se citó en Amasifuen, 2015) señala que: "La cultura tributaria se identifica con el cumplimiento voluntario de los deberes y obligaciones tributarios por parte del contribuyente y no con la implementación de estrategias para incrementar la recaudación de tributos bajo presión, por temor a las sanciones" (p.75).

Si bien la SUNAT principalmente tiene la finalidad de recaudar y fiscalizar tributos con el fin de brindar recursos financieros al Estado, y este pueda financiar las necesidades públicas, nos vemos inmersos en escenarios de informalidad y evasión tributaria, es así que, resulta oportuno plantear la estrategia de formar cultura tributaria a partir de la enseñanza de la tributación a niveles del sistema escolar, en tanto, pretender aplicar políticas tributarias, en una ciudadanía débil en valores, resultará un experimento que solamente castigue al formal y no se logre incluir al sector informal a la formalidad.

La Organización para la Cooperación y el Desarrollo Económicos - OCDE (2015) resalta la importancia y la utilidad de la temprana formación de contribuyentes en materia tributaria, ello con la finalidad de hacer frente al problema de la evasión tributaria, bajo la hipótesis de que a mediano plazo los contribuyentes informados, sensibilizados y comprometidos, asumirán la tributación con responsabilidad, y la incidencia se verá reflejada en una reducción de la evasión tributaria y en un incremento de la recaudación tributaria, es así que, sostiene: "La magnitud de la economía sumergida en la mayoría de los países en desarrollo se erige en el otro de los argumentos en favor de la Educación Cívico-Tributaria. Resulta más que plausible que un simple análisis de coste-beneficio revele que el hecho de perseguir a muchos contribuyentes potenciales, cuya aportación sería probable- 
mente mínima, consume más recursos de los que pretende generar. Sin embargo, la sensibilización y educación fiscal de dichos contribuyentes puede coadyuvar a fortalecer los sentimientos de responsabilidad y pertenencia o identificación con determinado estado" (p. 17).

\section{CONCLUSIÓN}

La obligación tributaria surge entre el acreedor y el sujeto pasivo, en cuanto acontezca el hecho previsto en la ley, es así que, el cumplimiento de la prestación tributaria se torna exigible coercitivamente en la medida que se incumpla total o parcialmente tal obligación. La obligación tributaria en el Perú, se encuentra establecida bajo el modelo de autoliquidación, es decir, el contribuyente es quien verifica la realización del hecho generador de la obligación, la misma que posteriormente podrá ser modificada por la Administración Tributaria, en tanto, constate omisión o inexactitud en la información declarada.

El cumplimiento de la obligación tributaria, exige al contribuyente verificar determinados deberes formales dependiendo el régimen tributario optado, su cumplimento parcial o tardío se encuentra sometido a sanciones, si bien se ha establecido supuestos de determinación y control, su incumplimiento se ha convertido en distintas formas de prácticas evasivas que han influido negativamente en la recaudación fiscal del estado.

Las últimas reformas tributarias tuvieron como objetivo minimizar el incumplimiento de la obligación tributaria. Sin embargo, nos encontramos ante escenarios de informalidad, y la conducta del contribuyente consiente el cumplimiento parcial o total de la obligación tributaria, es por ello, la necesidad de ejecutar políticas que estén ligados a mejorar la conducta del contribuyente en relación a la formación de cultura tributaria en el contribuyente.

En el estudio se ha justificado la importancia de educar al contribuyente sobre el rol social del tributo, la enseñanza de la tributación influiría en el proceso de socialización del contribuyente hacia actitudes favorables para el cumplimiento tributario voluntario, y contrario a las conductas evasivas. La incorporación de contenidos tributarios en el currículo escolar permite formar conciencia tributaria en los niños y jóvenes que en un mediano plazo se incorporarán a alguna actividad económica. 


\section{REFERENCIAS BIBLIOGRÁFICAS}

Aguayo, J. (2014). Derecho \& Sociedad. La Obligación Tributaria y el Pago: Antes del Inicio de la Cobranza Coactiva- en la Legislación Peruana. Recuperado de http://revistas.pucp.edu.pe/ index.php/

Amasifuen, M. (2015). Revista UPEU. Importancia de la cultura tributaria en el Perú. Recuperado de https://revistas.upeu.edu.pe/index.php/ri_apfb/article/

Bascuñan, S. (Julio de 2007). Elementos Fundamentales de la tributación en las empresas. Conferencia llevada a cabo en la Universidad Mayor, Santiago de Chile.

Bravo, J. (2006). Derecho \& Sociedad. Sistema tributario peruano: Situación actual y perspectivas. Recuperado de http://revistas.pucp.edu.pe/index.php/

Centro Interamericano de Administraciones Tributarias (CIAT) (2019). "Educación Tributaria" o "Tributación en la Educación”, un acercamiento diferente. Recuperado de https://www.ciat. org/educacion-tributaria-o-tributacion-en-la-educacion-un-acercamiento-diferente/

Corporación Latinobarómetro (2010). Informe Latinobarómetro 2010. Recuperado de http://www.latinobarometro.org/documentos/

Giarrizzo V. (2015). Cultura contributiva en América Latina. Evasión fiscal en la Argentina: caracterización del contribuyente según su predisposición a cumplir con sus impuestos. Argentina.

Instituto de Administración Tributaria y Aduanera [IATA-SUNAT]. (2010). Cultura tributaria: Libro de Consulta. Lima, Perú: SUNAT.

Instituto de Administración Tributaria y Aduanera [IATA-SUNAT]. (2012). Estrategia y Recursos Educativos para el Desarrollo de Conciencia Tributaria. Lima, Perú: SUNAT.

Moreno. D. y Moreno S. (2014). Derecho \& Sociedad. La Elusión Tributaria: Análisis Crítico de la Actual Normatividad y Propuestas para una Futura Reforma. Recuperado de http://revistas.pucp.edu.pe/index.php/

Ruiz de Castilla, F. (2010). Derecho \& Sociedad. La Obligación Tributaria y los Deberes Administrativos. Recuperado de http://revistas.pucp.edu.pe/index.php/

OECD/ Fundación Internacional y para Iberoamérica de Administración y Políticas Públicas (FIIAPP) (2015). Fomentando la cultura tributaria, el cumplimiento fiscal y la ciudadanía: Guía sobre educación tributaria en el mundo, OECD Publishing. Paris. Recuperado de https://read.oecd-ilibrary.org/taxation/fomentando-la-cultura-tributaria-el-cumplimientofiscal-y-la-ciudadania_9789264222786-es\#page4

Osterling, F. y Castillo F. (2001) Tratado de las obligaciones, Lima, Perú: Pontificia Universidad Católica del Perú.

Samuelson, P. y Nordhaus, W. (2004). Macroeconomía. Madrid, España: McGraw-Hill.

Solorzano D. (2008). La cultura tributaria, un instrumento para combatir la evasión tributaria en el Perú. Recuperado de http://www2.congreso.gob.pe/sicr/cendocbib/

SUNAT (2001). Tributemos. El cumplimiento voluntario es la voz. Recuperado de http://www. sunat.gob.pe/institucional/publicaciones/ 
SUNAT (2019). Cultura Tributaria y Aduanera. Núcleo de Apoyo Contable y Fiscal. Recuperado de https://cultura.sunat.gob.pe/nucleos-de-apoyo-contable-y-fiscal

Tribunal Constitucional del Perú - TC (2006). Sentencia del tribunal. Expediente N.o 6626-2006PA/TC. Recuperado de https://tc.gob.pe/jurisprudencia/

Valdivia, M. (2014). Administración Tributaria. Lima, Perú: Unión de la Universidad Peruana Unión.

Valdenebro, M. y Delgado M. (2010). La Educación Fiscal: ipor qué y para qué?. Madrid, España: Editorial MSImpresores, S. L.

Villegas, H. (2001). Curso de finanzas, derecho financiero y tributario. Buenos Aires, Argentina: Depalma. 